\title{
Comparison of different stomatal conductance algorithms for ozone flux modelling
}

\author{
P. Büker ${ }^{\text {a,* }}$, L.D. Emberson ${ }^{\text {a }}$, M.R. Ashmore ${ }^{\text {a }}$, H.M. Cambridge ${ }^{\text {a }}$, C.M.J. Jacobs ${ }^{b}$, \\ W.J. Massman ${ }^{c}$, J. Müller ${ }^{\mathrm{d}}$, N. Nikolov ${ }^{\mathrm{e}}$, K. Novak ${ }^{\mathrm{f}}$, \\ E. Oksanen ${ }^{\mathrm{g}}$, M. Schaub ${ }^{\mathrm{f}}$, D. de la Torre ${ }^{\mathrm{h}}$ \\ ${ }^{a}$ Stockholm Environment Institute, University of York, York, North Yorkshire YO $105 D D$, UK \\ ${ }^{\mathrm{b}}$ Alterra, Droevendaalsesteeg 3, 6708 PB Wageningen, The Netherlands \\ ${ }^{\circ}$ USDA Forest Service, Rocky Mountain Research Station, Fort Collins, CO, USA \\ 'Institute of Agronomy and Crop Science, Martin-Luther-University Halle-Wittenberg, Ludwig-Wucherer-Straß 2, D-06099 Halle, Germany

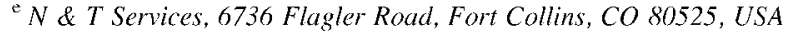 \\ ${ }^{\ulcorner}$Forest Ecosystems and Ecological Risk, Swiss Federal Research Institute WSL, Zuercherstraß 11], 8903 Birmensdorf ZH, Switzerland \\ ${ }^{g}$ Department of Biology, University of Joensuu, P.O. Box 111, 80101 Joensuu, Finland \\ ${ }^{\mathrm{h}}$ Institute for Energetics, Environment and Technological Research (CIEMAT), Avda. Complutense, 22, 28040, Madrid, Spain
}

\begin{abstract}
A multiplicative and a semi-mechanistic, BWB-type [Ball, J.T., Woodrow, I.E., Berry, J.A., 1987. A model predicting stomatal conductance and its contribution to the control of photosynthesis under different environmental conditions. In: Biggens, J. (Ed.), Progress in Photosynthesis Research, vol. IV. Martinus Nijhoff, Dordrecht, pp. 221-224.] algorithm for calculating stomatal conductance $\left(g_{\mathrm{s}}\right)$ at the leaf level have been parameterised for two crop and two tree species to test their use in regional scale ozone deposition modelling. The algorithms were tested against measured, site-specific data for durum wheat, grapevine, beech and birch of different European provenances. A direct comparison of both algorithms showed a similar performance in predicting hourly means and daily time-courses of $g_{s}$, whereas the multiplicative algorithm outperformed the BWB-type algorithm in modelling seasonal time-courses due to the inclusion of a phenology function. The re-parameterisation of the algorithms for local conditions in order to validate ozone deposition modelling on a European scale reveals the higher input requirements of the BWB-type algorithm as compared to the multiplicative algorithm because of the need of the former to model net photosynthesis $\left(A_{n}\right)$.
\end{abstract}

Keywords: Stomatal conductance; Photosynthesis; Modelling; Parameterisation

\section{Introduction}

Tropospheric or ground level ozone is a phytotoxic pollutant causing serious damage to agricultural productivity, forest health and semi-natural ecosystems (e.g. Ashmore, 2005). The extensive body of evidence, both observational and experimental, that has been collated since the first observations of ozone injury has provided the impetus to develop air quality management strategies and formulate emission reduction policies to limit the negative effects of this pollutant. During this time, an effect based approach, introduced by the United Nations Economic Commission for Europe Convention on Long-range Transboundary Air Pollution (CLRTAP) (Working Group on Effects, 2004), have provided the basis to characterise ozone 
concentrations so as to enable prediction of ozone levels above which significants effects may be discernable on vegetation. Initial attempts to characterise ozone concentrations led to the development of a number of different concentration based indices (e.g. Mauzerall and Wang, 2001) that attempt to relate ozone impacts to the measured or modelled ambient ozone concentrations. However, there is general consensus that ozone-induced phytotoxic effects such as foliar injury, premature senescence and reduced biomass are more closely related to the cumulative ozone uptake than to external ozone exposure (Fuhrer and Achermann, 1999; Massman et al., 2000; Wieser et al., 2000). This finding highlights the importance of the behaviour of the stomates, the main regulator of the gas exchange of plants, as being crucial in determining the potential damage caused by ozone. In order to perform pan European risk assessments, as are required to meet the needs of the UNECE CLRTAP, there is a need to be able to accurately model stomatal conductance (and hence ozone flux) for key species representing different vegetation types namely crops, forests and semi-natural vegetation. A combination of such a model, that also incorporates non-stomatal ozone deposition, with a regional scale photo-oxidant model provides estimates of total ozone flux or ozone deposition (e.g. Emberson et al., 2001; Simpson et al., 2003) and hence risk across broad geographical regions.

Despite evidence of stomatal behaviour being driven by environmental parameters such as photosynthetic photon flux density (PPFD), vapour pressure deficit (VPD), air temperature and soil water potential (SWP) (e.g. Jones, 1992), mechanistic models of stomatal conductance $\left(g_{s}\right)$ do not yet exist due to incomplete understanding of the complex physiological mechanisms of stomatal response to combinations of these parameters. Instead, (semi-)empirical approaches have been developed and proved successful in modelling stomatal conductance. Two types of algorithms have been widely used to predict stomatal conductance. The first is the multiplicative algorithm developed by Jarvis (1976) and further developed specifically to model ozone uptake to plants (e.g. Emberson et al., 2000; Grünhage et al., 2000) that calculates $g_{\mathrm{s}}$ as a function of phenology, PPFD, temperature, VPD and soil moisture related parameters. The second type of algorithm is the semi-mechanistic type of model that was initially developed by Ball et al. (1987), hereafter referred to as the BWB-algorithm. It is based on the evidence of a close relationship between $g_{\mathrm{s}}$ and net photosynthetic rate $\left(A_{\mathrm{n}}\right)$, which provides the link between the exchange of gases (e.g. $\mathrm{CO}_{2}, \mathrm{H}_{2} \mathrm{O}$, $\mathrm{O}_{3}$ ) and the prevailing climatic conditions. The BWB-algorithm calculates $g_{\mathrm{s}}$ as a function of $A_{\mathrm{n}}, \mathrm{CO}_{2}$ concentration and relative humidity, the two latter referring to the leaf surface. Stomatal responses to $\mathrm{CO}_{2}$, PPFD and temperature are included by means of an $A_{\mathrm{n}}$ model. In contrast with the multiplicative algorithm, these responses act synergistically.

Currently, the UNECE CLRTAP uses the EMEP photooxidant model (Simpson et al., 2003) to estimate ozone concentration profiles across Europe, in order to compare a range of different ozone precursor emission scenarios for policy evaluation. To assess ozone loss from the atmosphere to the ground surface the model employs an ozone deposition module referred to as $\mathrm{DO}_{3} \mathrm{SE}$ (Deposition of Ozone for Stomatal Exchange) that has been developed and applied specifically for use within the EMEP photo-oxidant model (Emberson et al., 2000; Simpson et al., 2003). $\mathrm{DO}_{3} \mathrm{SE}$ models both nonstomatal (e.g. leaf and soil surfaces) and stomatal deposition, the latter currently estimating stomatal conductance (for stomatal ozone flux) using a multiplicative based $g_{\text {s }}$ algorithm as described in Emberson et al. (2000) and Simpson et al. (2003).

The BWB-algorithm has become increasingly popular in combination with photosynthesis models (e.g. Farquhar et al., 1980) for plant growth simulations at different spatial scales (Nikolov and Zeller, 2003; Baldocchi, 1997; Arora, 2003). Since the BWB-algorithm offers the capability to model ozone-induced changes of the photosynthetic rate, it is of interest for ozone impact assessment (e.g. Weinstein et al., 1998).

However, few comparisons, all concentrating on tree species, of the performance of the two modelling approaches against measured stomatal conductance data have been presented so far (Van Wijk et al., 2000; Misson et al., 2004; Uddling et al., 2005). This paper reports a comparison of the ability of these two modelling approaches, represented by the $\mathrm{DO}_{3} \mathrm{SE}$ (multiplicative) and the LEAFC3 (BWB-algorithm) models to predict $g_{\mathrm{s}}$ for a range of species located across Europe. Nikolov et al. (1995) developed the generic leaf-level photosynthesis model LEAFC3 which implements a BWB-algorithm for the calculation of $g_{\mathrm{s}}$. The main aim of this study is to test how appropriate the two different $g_{\mathrm{s}}$ algorithms are for use in regional scale ozone deposition models. Therefore, both $g_{\mathrm{s}}$ modelling approaches have been evaluated focussing on (i) the model (input) requirements, (ii) the parameterisation requirements and (iii) the performance of the models in predicting $g_{\mathrm{s}}$ against site-specific data. The models were parameterised for two crop (grapevine (Vitis vinifera) and durum wheat (Triticum durum)) and two tree (beech ( $\mathrm{Fa}$ gus sylvatica) and birch (Betula pendula)) species and have been applied using data sets that have been collected from sites across Europe encompassing different European regions (North, Central and South Europe). The data sets each comprised the necessary environmental variables that are required as inputs to both models along with corresponding $g_{\mathrm{s}}$ observations.

\section{Data}

Four European data sets were identified to evaluate $g_{\mathrm{s}}$ predicted using the algorithms described above: (i) a Mediterranean grapevine data set from Spain (Jacobs et al., 1996), (ii) a boreal birch data set from Finland (Oksanen, 2003), (iii) a temperate beech data set from Switzerland (Novak, pers. comm.) and (iv) a Mediterranean wheat data set from Spain (de la Torre, 2004).

Tables 1 and 2 describe the four data sets, listing the range of the key meteorological, physiological and phenological variables. The model runs were performed using minute-by-minute (i.e. initial time steps of measurements) input data, however, 
Table 1

Description of locations, species, experiments and instruments used to provide stomatal conductance data

\begin{tabular}{|c|c|c|c|c|c|c|}
\hline Country & Site & Latitude & Longitude & Experimental set-up & $g_{\mathrm{s}}$-instrument & Species \\
\hline Spain & Tomelloso & $39^{\circ} 10^{\prime} \mathrm{N}$ & $3^{\circ} 1^{\prime} \mathrm{W}$ & Field & IRGA & Grapevine \\
\hline Spain & Alcalá de Henares & $40^{\circ} 31^{\prime} \mathrm{N}$ & $3^{\circ} 22^{\prime} \mathrm{W}$ & Field & IRGA & Durum wheat \\
\hline Switzerland & Lattecaldo & $45^{\circ} 51^{\prime} \mathrm{N}$ & $9^{\circ} 3^{\prime} \mathrm{E}$ & OTC & IRGA & Beech \\
\hline Finland & Kuopio & $62^{\circ} 13^{\prime} \mathrm{N}$ & $27^{\circ} 35^{\prime} \mathrm{E}$ & Field & Porometer & Birch \\
\hline
\end{tabular}

the results are presented as hourly means. The conversion to hourly means ensures that $g_{\text {s }}$ measurements reflect the prevailing meteorological conditions since it is acknowledged that changes in $g_{\mathrm{s}}$ will often lag behind changes in environmental variables and are consistent with the time step used in regional scale deposition modelling. Additional analysis was also performed with pooled $g_{\mathrm{s}}$ data to provide diurnal and seasonal time courses of $g_{\mathrm{s}}$ allowing analysis of the algorithm's ability to predict the general temporal trends in stomatal conductance. Note that the beech data set contains a constant PPFD-value of $1500 \mu \mathrm{mol} \mathrm{m}{ }^{-2} \mathrm{~s}^{-1}$.

A common problem with all data sets was the lack of information describing soil water status, a variable necessary as input to both $g_{\mathrm{s}}$ models. As such, it has been necessary to assume that water availability was not limiting to $g_{\text {s }}$ over all observation periods. Although this might reduce the predictive performance of the $g_{\mathrm{s}}$ models, the results should still be comparative between models since the assumption of non-limiting soil water is consistent between algorithms.

\section{Modelling}

\subsection{Model formulation}

The multiplicative $g_{\mathrm{s}}$ algorithm currently used in the $\mathrm{DO}_{3} \mathrm{SE}$ model is given in Eq. (1) and described in more detail in Emberson et al. (2000).

$g_{\text {sto }}=g_{\text {max }} f_{\text {phen }} f_{\text {light }} \max \left\{f_{\text {min }}\left(f_{\text {temp }} f_{\mathrm{VPD}} f_{\mathrm{SWP}}\right)\right\}$

where $g_{\text {sto }}\left(\mathrm{mmol} \mathrm{O}_{3} \mathrm{~m}^{-2} \mathrm{~s}^{-1}\right)$ is the actual $g_{\mathrm{s}}$ and $g_{\max }(\mathrm{mmol}$ $\mathrm{O}_{3} \mathrm{~m}^{-2} \mathrm{~s}^{-1}$ ) is the maximum $g_{\mathrm{s}}$ occurring during the growing season. The factors $f_{\text {phen }}, f_{\text {light }}, f_{\text {temp }}, f_{\text {VPD }}$ and $f_{\text {SWP }}$ represent the modification of $g_{\max }$ due to leaf phenology, irradiance, air temperature, vapour pressure deficit (VPD) and soil water potential (SWP), respectively. $f_{\min }$ represents the minimum daytime $g_{\text {s }}$ observed under field conditions before the onset of permanent wilting point (PWP). All the $f$ functions are expressed in relative terms between 0 and 1 .

The photosynthesis-based algorithm is given in Eq. (2) as described in Nikolov et al. (1995).

$g_{\text {sto }}=g_{\min }+m A_{\mathrm{n}} \frac{h_{\mathrm{b}}}{C_{\mathrm{b}}}$

where $g_{\text {sto }}\left(\mathrm{mmol} \mathrm{O}_{3} \mathrm{~m}^{-2} \mathrm{~s}^{-1}\right)$ is the actual $g_{\mathrm{s}}, g_{\min }\left(\mathrm{mmol} \mathrm{O}_{3}\right.$ $\left.\mathrm{m}^{-2} \mathrm{~s}^{-1}\right)$ is the minimum daytime $g_{\mathrm{s}}$ observed under field conditions, $A_{\mathrm{n}}\left(\mu \mathrm{mol} \mathrm{CO} 2 \mathrm{~m}^{-2} \mathrm{~s}^{-1}\right.$ ) is the net assimilation rate and $m$ is a dimensionless slope representing the species-specific composite sensitivity of $g_{\mathrm{s}}$ to $A_{\mathrm{n}}$, the $\mathrm{CO}_{2}$ concentration at the leaf surface $\left(C_{\mathrm{b}} ; \mu \mathrm{mol} \mathrm{mol}{ }^{-1}\right)$ and the relative humidity at the leaf surface ( $h_{\mathrm{b}}$; decimal fraction). $A_{\mathrm{n}}$ can either be supplied from measured data or, as in LEAFC3, modelled as a function of irradiance and temperature according to Farquhar et al. (1980). These two environmental parameters define the plant's biochemical activity by directly influencing the species-specific maximum rate of carboxylation $\left(V_{\mathrm{cmax}}\right)$ and electron transport $\left(J_{\max }\right)$.

\subsection{Model parameterisation}

When considering the suitability of the two algorithms described above for use in $\mathrm{DO}_{3} \mathrm{SE}$ and hence application at the regional scale, it is important to consider how well a generic parameterisation is able to represent individual species at specific locations. As such the default parameterisation of the multiplicative model (i.e. the current $\mathrm{DO}_{3} \mathrm{SE}$ parameterisation), and where possible, literature based parameterisation of the BWB-model is shown in relation to local values in Tables 3 and 4 . The use of local parameterisation in the model runs performed ensured that model comparisons were affected as little as possible by difficulties associated with establishing parameterisation of model functions for site-specific locations. However, it should be noted that local parameterisation is

Table 2

Range of main meteorological, physiological and phenological parameters for grapevine, wheat, beech and birch (value in brackets indicates mean)

\begin{tabular}{|c|c|c|c|c|c|}
\hline Parameter & Grapevine & Wheat & Beech & Birch & Units \\
\hline Temperature & $13.1-40.0(28.4)$ & $18.0-43.2(30.5)$ & $21.2-31.7(26.8)$ & $14.8-23.6(20.0)$ & ${ }^{\circ} \mathrm{C}$ \\
\hline VPD & $0.5-5.9(2.7)$ & $0.2-7.3(2.7)$ & $1.0-2.8(1.8)$ & $0.1-1.6(1.0)$ & $\mathrm{kPa}$ \\
\hline PPFD & $2.0-2133.0(784.6)$ & $65.0-2349.7(1360.0)$ & 1500.0 (constant) & $10.0-1870.0(762.8)$ & $\mu \mathrm{mol} \mathrm{m}{ }^{-2} \mathrm{~s}^{-1}$ \\
\hline$g_{\mathrm{s}}$ & $1.7-251.3(97.8)$ & $21.8-504.0(169.4)$ & $22.4-714.0(216.9)$ & $13.5-450.6(181.1)$ & $\mathrm{mmol} \mathrm{H}_{2} \mathrm{O} \mathrm{m}^{-2} \mathrm{~s}^{-1}$ \\
\hline$A_{\mathrm{n}}$ & $-0.2-20.7(7.9)$ & $-0.4-46.5(11.9)$ & $1.9-15.2(9.1)$ & - & $\mu \mathrm{mol} \mathrm{CO} \mathrm{m}^{-2} \mathrm{~s}^{-1}$ \\
\hline $\begin{array}{l}\text { Measuring period } \\
\text { (no. of measuring days) }\end{array}$ & $17 / 6-28 / 6(7)$ & $19 / 4-12 / 6(16)$ & $11 / 5-4 / 10(9)$ & $18 / 6-1 / 8(11)$ & - \\
\hline$n$ & 615 & 193 & 272 & 1246 & - \\
\hline
\end{tabular}


Table 3

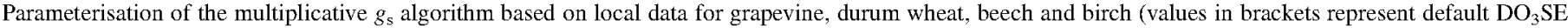
parameterisation as described in Simpson et al. (2003) and Emberson et al. (2005a,b)

\begin{tabular}{|c|c|c|c|c|c|}
\hline Parameter & Grapevine & Wheat & Beech & Birch & Units \\
\hline$g_{\max }$ & $153(215)$ & $310(450)$ & $340(140)$ & $200(275)$ & $\mathrm{mmol} \mathrm{O}_{3} \mathrm{~m}^{-2}$ PLA s $^{-1}$ \\
\hline$f_{\min }$ & $0.1(0.01)$ & $0.03(0.01)$ & $0.1(0.13)$ & $0.1(0.13)$ & Fraction \\
\hline SGS & $120(120)$ & $109(119)$ & $120(90)$ & $140(90)$ & Day of year \\
\hline EGS & $300(300)$ & $164(174)$ & $310(270)$ & $263(270)$ & Day of year \\
\hline$f_{\text {Phen_a }}$ & $0.05(0.2)$ & $0.5(0.8)$ & $0.1(0.3)$ & $0.1(0.3)$ & Fraction \\
\hline$f_{\text {phen_b }}$ & $40(60)$ & $35(15)$ & $100(50)$ & $30(50)$ & Days \\
\hline$f_{\text {phen_c }}$ & $70(45)$ & $12(40)$ & $40(50)$ & $30(50)$ & Days \\
\hline light_a & $0.002(0.0076)$ & $0.01(0.0105)$ & $0.026(0.006)$ & $0.001(0.006)$ & Constant \\
\hline$T_{\min }$ & $9(9)$ & $7(12)$ & $17(-5)$ & $-5(-5)$ & ${ }^{\circ} \mathrm{C}$ \\
\hline$T_{\mathrm{opt}}$ & $32(30)$ & $34(26)$ & $25(22)$ & $20(22)$ & ${ }^{\circ} \mathrm{C}$ \\
\hline$T_{\max }$ & $45(43)$ & $50(40)$ & $39(35)$ & $39(35)$ & ${ }^{\circ} \mathrm{C}$ \\
\hline$V P D_{\max }$ & $0.6(1.6)$ & $2.3(1.2)$ & $1.1(0.93)$ & $0.9(0.93)$ & $\mathrm{kPa}$ \\
\hline$V_{P D} \min$ & $6.2(6.2)$ & $6.9(3.2)$ & $3.0(3.4)$ & $3.0(3.4)$ & $\mathrm{kPa}$ \\
\hline
\end{tabular}

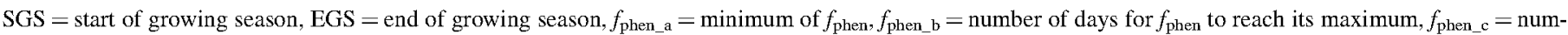
ber of days for $f_{\text {phen }}$ during decline to again reach the minimum. PLA $=$ Projected Leaf Area.

more easily defined for the multiplicative algorithm (which assumes model functions to be independent of each other) than for the photosynthesis-based algorithm (in which parameters such as $V_{\text {cmax }}$ and $J_{\max }$ are closely related to each other (cf. Leuning, 2002)).

Table 3 lists the input parameters required by the multiplicative $g_{\mathrm{s}}$ algorithm and their site-specific parameterisation for grapevine, durum wheat, beech and birch. The site-specific parameterisation was achieved by fitting boundary lines to the $g$ s relationships that gave optimal model performance in comparison with observations. The default $\mathrm{DO}_{3} \mathrm{SE}$ parameterisation representing mean European growing conditions is shown in brackets. Definitions of the functions representing the relationships between $g_{\mathrm{s}}$ and environmental and phenological parameters can be found in Emberson et al. (2000). It should be noted that the wheat site-specific parameterisation is for $T$. durum, whereas the $\mathrm{DO}_{3} \mathrm{SE}$ model is only parameterised for Triticum aestivum.

Table 4 shows the main input parameters required by LEAFC3 and its parameterisation for the same species as mentioned above. Note that apart from $m$ all shown parameters are related to the photosynthesis module of $\mathrm{LEAFC} 3$. To represent local conditions, the parameters $m, V_{\mathrm{m} 25}\left(V_{\mathrm{cmax}}\right.$ at $\left.25^{\circ} \mathrm{C}\right)$ and $J_{\mathrm{m} 25}\left(J_{\max }\right.$ at $\left.25^{\circ} \mathrm{C}\right)$ were adjusted: $m$ has been calculated according to a methodology described in Müller et al. (2005) which uses measured data. However, for birch no measured
$A_{\mathrm{n}}$ data were available, and therefore a value provided by Nikolov (1997) for deciduous trees was used. $V_{\mathrm{m} 25}$ and $J_{\mathrm{m} 25}$ were varied within a data range (see brackets) derived from a comprehensive literature review, always ensuring a ratio $J_{\mathrm{m} 25} / V_{\mathrm{m} 25}$ of $2.0 \pm 0.6$ as suggested by Leuning (2002). The temperature response functions (not shown) for the parameters $J_{\mathrm{m} 25}, R_{\mathrm{d}}$ (mitochondrial respiration), $\Gamma$ ( $\mathrm{CO}_{2}$ compensation point in the absence of mitochondrial respiration), $K_{\mathrm{c} 25}$ and $K_{\mathrm{O} 25}$ (Michaelis-Menten constant of Rubisco for carboxylation and oxygenation at $25^{\circ} \mathrm{C}$, respectively) were taken from a recently published revision of LEAFC3 by Müller et al. (2005), whereas the temperature response function for $V_{\mathrm{m} 25}$ remained the same as in Nikolov et al. (1995). For $\mathrm{C}_{3}$ plants the parameters $K_{\mathrm{c} 25}$ and $K_{\mathrm{o} 25}$ (Table 4 ) only vary within a small range and therefore were considered to be constant here with values according to Bernacchi et al. (2001).

\section{Results}

Based on both algorithms, Table 5 shows the percentage of the variation in observed values that is explained by the two models, averaged over hourly, daily and seasonal time steps. This comparison reveals a substantial amount of unexplained variation, in particular for the data set of hourly means, for which the unexplained variation ranges from $77 \%$ (wheat using the multiplicative algorithm) to $33 \%$ (beech using

Table 4

Parameterisation of LEAFC3 for grapevine, wheat, beech and birch based on published data and calculations using local data (italics)

\begin{tabular}{|c|c|c|c|c|c|c|}
\hline Parameter & Grapevine & Wheat & Beech & Birch & Units & Reference \\
\hline$m$ & 6.14 & 8.12 & $16.83^{*}$ & 13.5 & - & $\begin{array}{l}\text { After Müller et al. (2005), } \\
\text { Nikolov et al. (1995) }\end{array}$ \\
\hline$V_{\mathrm{m} 25}$ & $100(50-100)$ & $180(25-261)$ & $30(28-66)$ & $35(28-169)$ & $\mu \mathrm{mol} \mathrm{m} \mathrm{s}^{-2} \mathrm{~s}^{-1}$ & See text \\
\hline$J_{\mathrm{m} 25}$ & $225(120-260)$ & $400(87-522)$ & $60(52-128)$ & $70(80-230)$ & $\mu \mathrm{mol} \mathrm{m}{ }^{-2} \mathrm{~s}^{-1}$ & See text \\
\hline$K_{\mathrm{c} 25}$ & 404.09 & 404.09 & 404.09 & 404.09 & $\mu \mathrm{mol} \mathrm{\textrm {mol } ^ { - 1 }}$ & Bernacchi et al. (2001) \\
\hline$K_{\mathrm{o} 25}$ & 278.40 & 278.40 & 278.40 & 278.40 & $\mathrm{mmol} \mathrm{mol}^{-1}$ & Bernacchi et al. (2001) \\
\hline$g_{\min }$ & 0.05 & 0.02 & 0.03 & 0.03 & $\mathrm{~mol} \mathrm{~m}^{-2} \mathrm{~s}^{-1}$ & Obtained from $g_{s}$ in dark \\
\hline
\end{tabular}

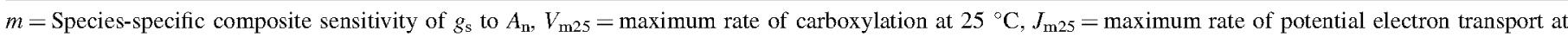

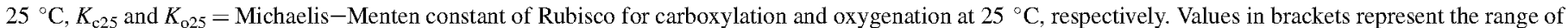
$V_{\mathrm{m} 25}$ and $J_{\mathrm{m} 25}$ derived from a comprehensive literature review. 
Table 5

Performance $\left(R^{2}\right.$-values of observed vs. modelled $\left.g_{s}\right)$ of both algorithms applied to four different data sets representing grapevine, wheat, birch and beech

\begin{tabular}{|c|c|c|c|c|c|c|}
\hline & \multicolumn{2}{|l|}{ Hourly means } & \multicolumn{2}{|l|}{ Diurnal course } & \multicolumn{2}{|l|}{ Seasonal course } \\
\hline & Multiplicative & BWB & Multiplicative & BWB & Multiplicative & BWB \\
\hline Grapevine (Vitis vinifera) & $0.39(9.49 ; 10.13)$ & $0.40(4.83 ; 5.16)$ & 0.77 & 0.78 & - & - \\
\hline Wheat (Triticum durum) & $0.23(-59.79 ; 31.19)$ & $0.29(11.44 ; 5.97)$ & 0.72 & 0.82 & - & - \\
\hline Birch (Betula pendula) & $0.30(40.04 ; 23.08)$ & $0.33(2.37 ; 1.37)$ & 0.48 & 0.32 & 0.55 & 0.45 \\
\hline Beech (Fagus sylvatica) & $0.67(-26.76 ; 12.01)$ & $0.04(18.62 ; 8.36)$ & 0.95 & 0.62 & 0.77 & 0.03 \\
\hline
\end{tabular}

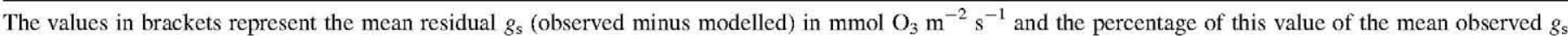

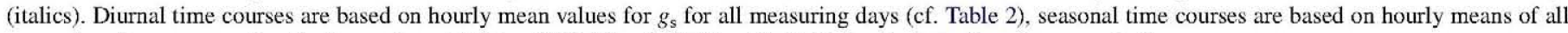
measuring days representing the hours from 11:00 until 13:00 and 10:00 until 14:00 for birch and beech, respectively.

multiplicative algorithm) (Table 5). Apart from the beech data set, which was of limited use for testing the BWB-algorithm due to its constant PPFD-value, the differences in performance between multiplicative and BWB-algorithm were small.

The mean residuals (observed minus modelled) of hourly $g_{\mathrm{s}}$ values were higher for the multiplicative than the BWBalgorithm, with the application of the former leading on average to an over-prediction of $g_{\mathrm{s}}$ for wheat $(31.19 \%$ of mean observed $g_{\mathrm{s}}$ ) and beech $(12.01 \%)$ and an under-prediction for birch $(23.08 \%)$ and grapevine $(10.13 \%)$ (Table 5). The BWB-algorithm on average underpredicted $g_{\mathrm{s}}$ for all species. However, the residuals were always less than $10 \%$ of the mean observed $g_{\mathrm{s}}$.

The ability of the models to predict mean diurnal time courses of $g_{\mathrm{s}}$ was consistently greater than their ability to predict individual hourly mean values (Table 5), except for the BWB-algorithm with birch. The diurnal $g_{\mathrm{s}}$-profiles based on hourly means showed good correspondence between observed and modelled data for grapevine and wheat (Table 5, Figs. 1 and 2). In terms of grapevine, both algorithms performed well for the morning hours before showing an increase in divergence between observed and modelled data in the afternoon (Fig. 1). Only the observed $g_{\mathrm{s}}$-peak at 4 p.m., which is the mean of two measuring days, wasn't predicted by either algorithm. The multiplicative algorithm generally led to an over-prediction of $g_{\mathrm{s}}$ for wheat (Fig. 2) and an under-prediction for birch (Fig. 3), whereas the BWB-algorithm over-predicted $g_{\mathrm{s}}$ for the midday hours but under-predicted it in the morning (only for wheat) and afternoon for both wheat and birch. In general, the modelled diurnal $g_{\mathrm{s}}$-courses for birch showed only small amplitudes when compared with observed data (Fig. 3). Fig. 4 again demonstrates the difficulties of applying the BWB-algorithm to the beech data set, whereas the multiplicative algorithm performs much better with a slight over-prediction of $g_{\mathrm{s}}$ between 10 a.m. and 12 a.m. However, no statements can be made regarding the performance of both algorithms for afternoon hours because of a lack of data for that time-period.

In order to test the algorithms' ability to account for the variation in $g_{\mathrm{s}}$ over the course of the growing season due to changes in plant-physiological activity, seasonal profiles of modelled and observed midday- $g_{\mathrm{s}}$ for birch and beech are shown in Figs. 5 and 6, respectively. For birch, the fit between modelled and observed $g_{\mathrm{s}}$ was improved using daily means when compared with individual hourly means (Table 5). Though generally showing a good fit, the modelled $g_{s}$ increasingly differed from the observed $g_{s}$ later in the growing season. In contrary, for beech the multiplicative algorithm performed better from August on as compared with the beginning of the growing season, whereas the BWB-algorithm could not reproduce the observed seasonal variation at all.

A similar comparison for the crop species was not possible due to the nature of the input data.

\section{Discussion}

The performance of both modelling approaches, when assessed on an hourly mean basis, is generally rather similar, with the exception of beech for which the multiplicative model performs far better than the BWB-algorithm (with $R^{2}$ values of 0.67 and 0.04 , respectively). However, in comparison with the
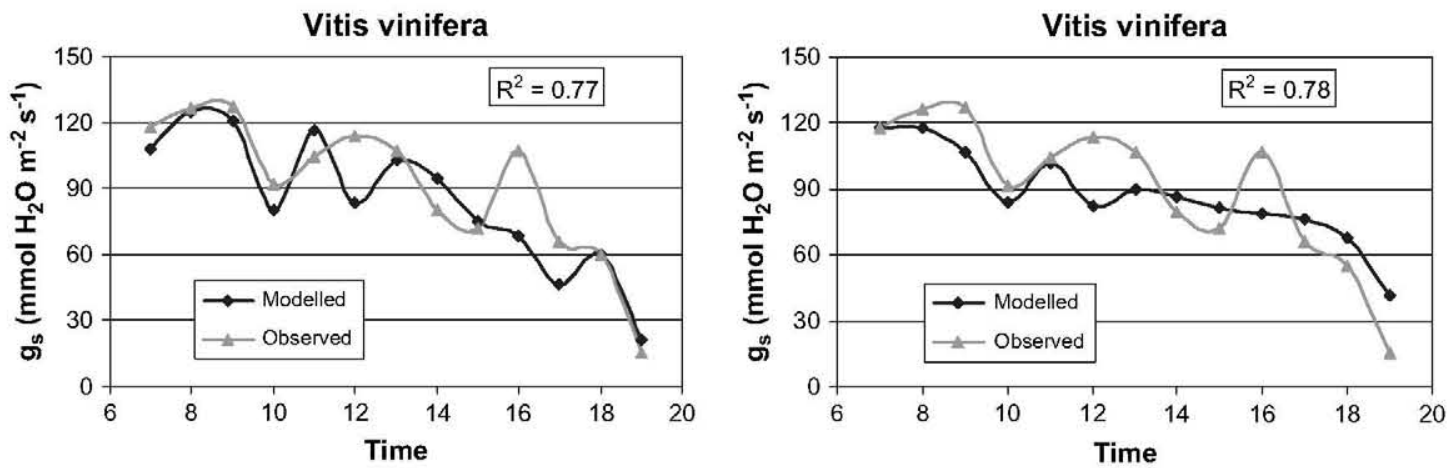

Fig. 1. Daily time course (07:00-19:00 hrs) of modelled and observed $g_{\mathrm{s}}\left(\mathrm{mmol} \mathrm{H}_{2} \mathrm{O} \mathrm{m}^{-2} \mathrm{~s}^{-1}\right)$ averaged over 7 days in June 1991 for Mediterranean grapevine using the multiplicative algorithm (left) and the BWB-algorithm (right). 
Triticum durum

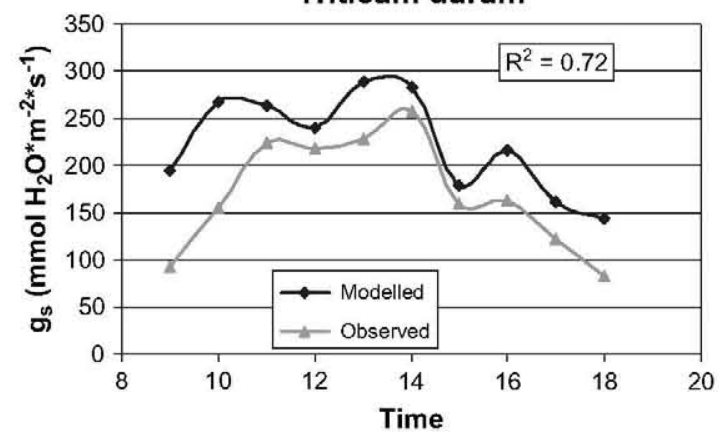

Triticum durum

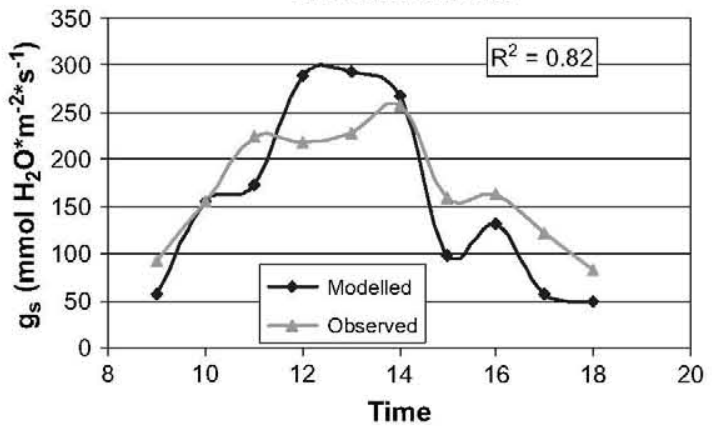

Fig. 2. Daily time course (09:00-18:00 hrs) of modelled and observed $g_{\mathrm{s}}\left(\mathrm{mmol} \mathrm{H}_{2} \mathrm{O} \mathrm{m}^{-2} \mathrm{~s}^{-1}\right)$ averaged over 16 days between April and June 2000,2001 and 2002 for Mediterranean durum wheat flag leaves using the multiplicative algorithm (left) and the BWB-algorithm (right).

BWB-algorithm, there is greater systematic bias in the $g_{s}$ predictions using the multiplicative algorithm (Table 5). It is evident that both models are not performing as well as have been found in other similar studies (e.g. Van Wijk et al., 2000; Misson et al., 2004; Uddling et al., 2005). Jacobs et al. (1996) applied a photosynthetic-based algorithm to the grapevine data set presented here and obtained $R^{2}$ values of up to 0.66 between predicted and observed values of $g_{\mathrm{s}}$. The better performance of all these studies may well be due to their site-specific scope, developing formulations (not just parameterisations) that may be more representative of local conditions at particular sites. This was not possible or desirable in this study since the intention here is to compare predictive capabilities of the models designed for generic application over broad geographical scales.

However, when the models are compared over diurnal and seasonal time courses the results appear to improve, indicating that both modelling approaches are capable of capturing major temporal trends in conductance. The commonly observed midday depression for $g_{\mathrm{s}}$ - as seen here for wheat, birch and to a lesser extent grapevine, but not for beech - and the decline of $g_{\mathrm{s}}$ in the afternoon hours was predicted by both algorithms.

Arguably, in terms of modelling stomatal ozone uptake these general trends are more important than individual hourly means, as ensuring that the appropriate co-variation in $g_{\mathrm{s}}$ with the variation in ozone concentrations is crucial since the advantage of the flux-based approach is often cited as the ability to predict when stomatal responses will constrain ozone uptake at elevated ozone concentration. In using seasonal cumulative flux indices, it is the ability to predict diurnal and seasonal variations with precision that is more important than the ability to predict every hourly mean value accurately.

The fact that both models seem capable of predicting afternoon closure of the stomata, which is likely to be driven by increasing atmospheric water deficits (e.g. as observed for grapevine and wheat), might indicate that appropriate $g_{\mathrm{s}}$ responses are being modelled for prevailing environmental conditions. In addition, the ability of the models to simulate the rather constant $g_{\mathrm{s}}$ values of birch (which are probably due to the measurement period being only between the hours of 10.00 and $15.00 \mathrm{hrs}$ ) also indicates that the models can simulate near optimal conditions reasonably well (the observed $g_{\mathrm{s}}$ values are close to the maximum for this species).

The improved model results for wheat using the BWBalgorithm may be explained by the optimisation of the LEAFC3 model parameterisation for this species published by Müller et al. (2005), which was implemented where appropriate in the modelling applied in this analysis. For beech, the multiplicative model performs better diurnally; the poor performance of the BWB-algorithm is most likely related to the fact that the saplings were observed under constant saturated light conditions, which will result in a lack of variation in $g_{\mathrm{s}}$ since light is a key driver of $A_{\mathrm{n}}$.

Over the seasonal time course the multiplicative model consistently outperformed the BWB-algorithm for both beech and birch. This is to be expected since the multiplicative model incorporates a phenology function in contrast to the
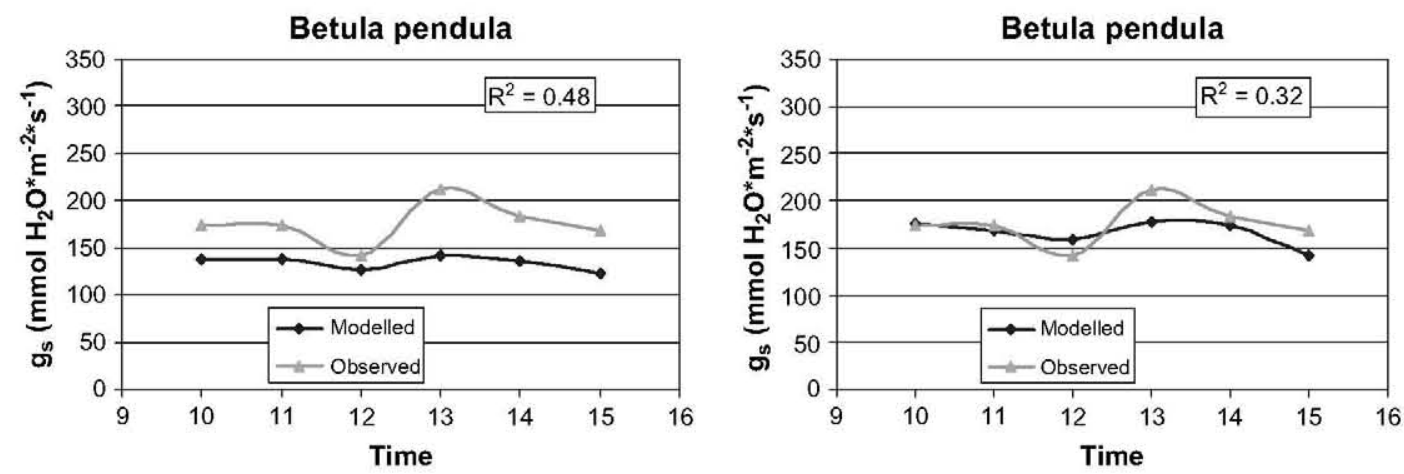

Fig. 3. Daily time course (10:00-15:00 hrs) of modelled and observed $g_{\mathrm{s}}\left(\mathrm{mmol} \mathrm{H}_{2} \mathrm{O} \mathrm{m}^{-2} \mathrm{~s}^{-1}\right)$ averaged over 11 days between June and August 2001 for boreal birch using the multiplicative algorithm (left) and the BWB-algorithm (right). 
Fagus sylvatica

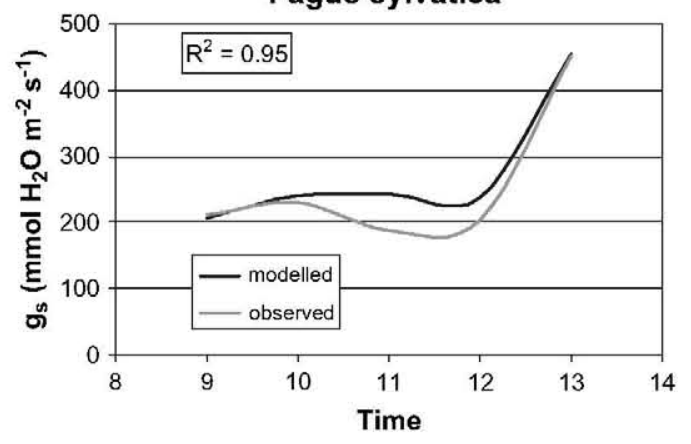

Fagus sylvatica

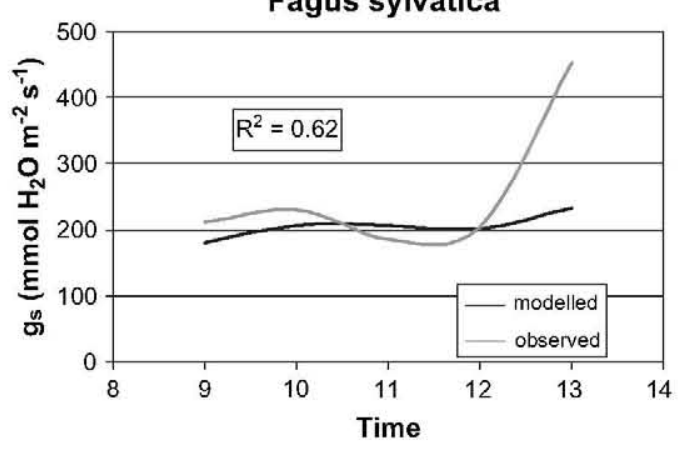

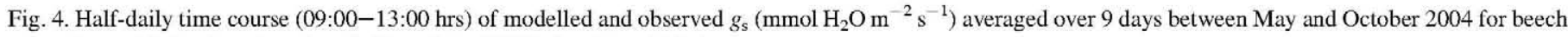
using the multiplicative algorithm (left) and the BWB-algorithm (right).

BWB-algorithm. The inability to account for seasonally determined modulation in $g_{\mathrm{s}}$ is often cited as a problem related to the BWB-type models. One way to overcome this problem is the introduction of a parameter representing the variation in photosynthetic capacity over the course of the growing season, such as the leaf nitrogen content. For example, Müller et al. (2005) have developed a nitrogen-sensitive extension of the LEAFC3 model which improved the predictive performance when being applied to wheat.

One of the key issues in the overall comparison work performed here is that of parameterisation of the models. Firstly, it should be recognised that re-parameterisation for local conditions is far easier to achieve for the multiplicative model since this algorithm assumes that all required variables are independent of each other. However, this is also a weakness of the multiplicative algorithm, since in nature the variables are often dependant and act synergistically. Previous studies (e.g. Emberson et al., 2000; Tuovinen et al., 2001) have highlighted the strong dependency of the multiplicative model on $g_{\max }$. In the modelling performed here the uncertainty in this parameter is reduced since $g_{\max }$ is here derived from the data sets. However, the importance of this parameter is clearly demonstrated by this analysis since the local $g_{\max }$ values for grapevine, wheat and beech are rather different from the $\mathrm{DO}_{3} \mathrm{SE}$ model default $g_{\max }$ values, although in the case of beech this may well be explained by growth of the saplings in open top chambers. The difference between observed and predicted daily courses of $g_{\mathrm{s}}$ using the multiplicative algorithm for wheat and birch is likely to be related to the fact that the $g_{\max }$ values used in this study were derived from primary data sets, hence might not represent optimal species-specific gas exchange conditions.

In terms of the other multiplicative model parameters, those that deviate most from the default values are the $f_{\text {temp }}$ and $f_{\mathrm{VPD}}$ functions. In terms of wheat, this is not surprising since the default data are for $T$. aestivum, whereas this study used $T$. durum. The latter is better adapted to local Mediterranean conditions which require the capacity to maintain gas exchange at higher temperatures and atmospheric water deficits than more temperate counterparts. This is also the case for the grapevine cultivar used here, which is well adapted to Mediterranean climates, whereas the default parameterisations account for grapevine grown in Central Europe.

For the BWB-algorithm, the key species-specific parameters (i.e. $V_{\mathrm{m} 25}, J_{\mathrm{m} 25}$ and their associated temperature response functions) were defined based on published values. Table 4 shows that the range in these values, even within species, is large and the local parameterisation tends towards the extremes of the range. In addition, the parameterisation of the parameter $m$ of the BWB-algorithm is essential because it defines the "composite sensitivity" of $g_{\mathrm{s}}$ to $A_{\mathrm{n}}$. Several studies (Wohlfahrt et al., 1998; Kosugi et al., 2003; Müller et al.,

\section{Betula pendula}

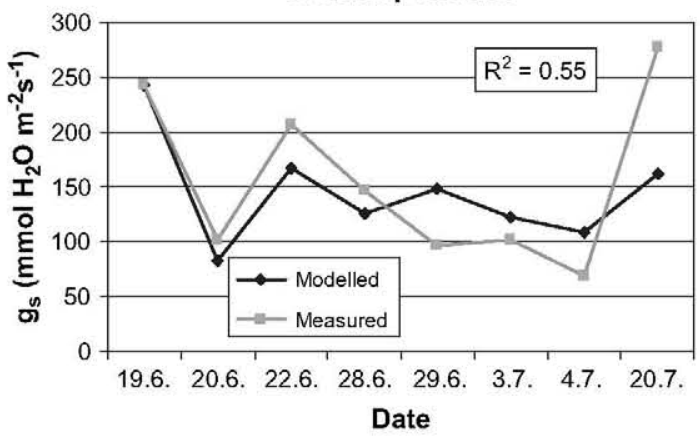

Betula pendula

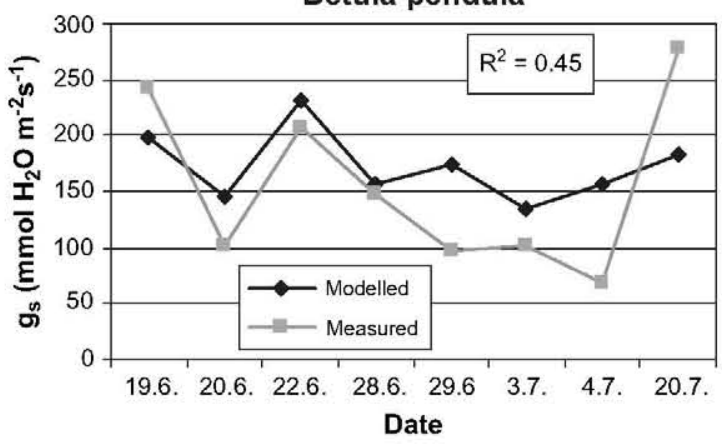

Fig. 5. Seasonal time course (5 weeks during the summer of 2001) of modelled and observed $g_{\mathrm{s}}\left(\mathrm{mmol} \mathrm{H}_{2} \mathrm{O} \mathrm{m}^{-2} \mathrm{~s}^{-1}\right)$ averaged over midday hours $(11: 00-13: 00$ hrs) for boreal birch using the multiplicative algorithm (left) and the BWB-algorithm (right). 
Fagus sylvatica

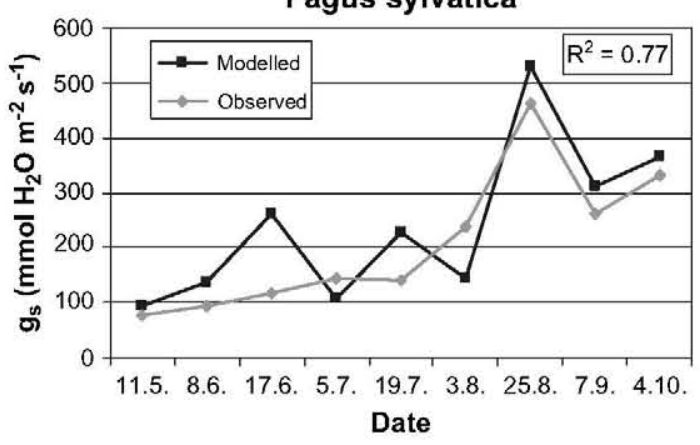

Fagus sylvatica

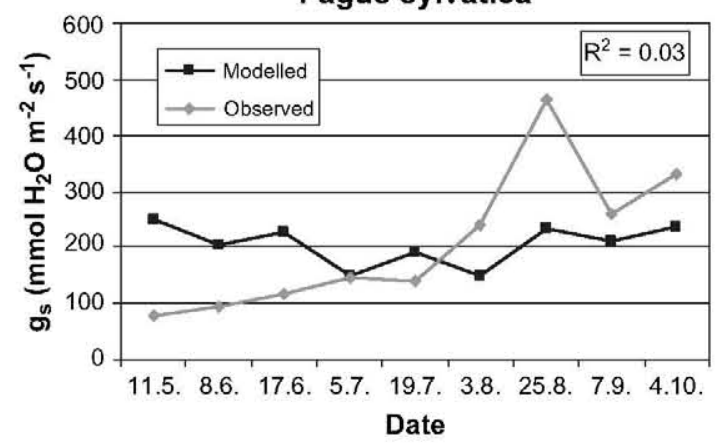

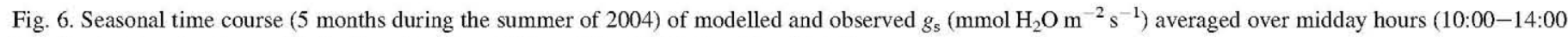
hrs) for beech using the multiplicative algorithm (left) and the BWB-algorithm (right).

2005) have shown that this parameter might change with leaf age, which was not accounted for in this study. However, the parameterisation of $m$ for the four species used here is in good agreement with published values for various crop and tree species (cf. Wullschleger, 1993).

Leuning (1995) stressed the theoretical weakness of the BWB-type models because of their reliance on relative humidity rather than VPD. It has been shown that evaporative loss is a main driver for stomatal aperture, which can be expressed by VPD changes but not by changes in relative humidity. However, there is evidence that when applying BWB-type models to field data showing varying VPD values due to temperature changes, as is the method used here, the predictive performance of both approaches (relative humidity vs. VPD) is very similar.

One of the key limitations to this comparison has been the inability to incorporate the effects of soil moisture deficit (SMD) on $g_{s}$. Although not used in this analysis due to the lack of data describing the water status of the soil system, both algorithms do have the capability to predict drought effects on $g_{s}$. The multiplicative algorithm used in $\mathrm{DO}_{3} \mathrm{SE}$ incorporates a relationship relating soil water potential (derived from $g_{\mathrm{s}}$ observations with pre-dawn leaf water potential) to $g_{\mathrm{s}}$, whereas LEAFC3 accounts indirectly for the effect of SMD on stomata via the alteration of $m$ as a function of leaf water potential (Nikolov et al., 1995).

Finally, the main purpose of this paper was to assess both models, performance in the context of their applicability for use within a regional scale ozone deposition model (e.g. $\mathrm{DO}_{3} \mathrm{SE}$ ). The higher input requirements of the BWB-algorithm are an obvious limitation (both in terms of input and parameterisation data) to application at the regional scale. The main reason for this is that net photosynthesis $\left(A_{\mathrm{n}}\right)$ is required as an input parameter. Since information on $A_{n}$ is not always readily available, and certainly not available on a regional scale, BWB-type models are often connected with photosynthesis models (e.g. LEAFC3) which require detailed and species-specific plant-physiological input parameters (e.g. $V_{\mathrm{m} 25}$, $\left.J_{\mathrm{m} 25}, K_{\mathrm{c} 25}, K_{\mathrm{o} 25}\right)$ which are often difficult to obtain. In fact, in the absence of experimental plant-physiological (primary) data, users usually have to rely on secondary data from the literature. As such, even though the semi-mechanistic nature of the BWB-algorithm provides a more process-based approach to modelling $g_{\mathrm{s}}$, this may not be perceived as reason enough given the increased data requirements and model run times that would be necessary for a regional scale application of the model for ozone deposition studies. In addition, since the results presented in this paper do not show significant improvements in the prediction of $g_{\mathrm{s}}$ using the BWB-algorithm compared with the multiplicative algorithm (in some cases the predications are less favourable, especially over a seasonal time course) it would not seem appropriate to suggest using such models in present-day regional scale deposition modelling schemes.

However, while the multiplicative algorithm might be favourable for regional scale $g_{\mathrm{s}}$ predictions, the photosynthesis-based algorithm might give beneficial additional information on the relationship between ozone flux and impacts on a local scale, provided that key parameters are available. In particular, photosynthesis-based models provide a means of linking ozone uptake directly to effects on photosynthesis making it possible to perform process growth modelling to understand ozone sensitivities to carbon dynamics, e.g. carbon allocation assessments (e.g. as possible with the TREGRO model of Weinstein et al., 1991).

In the longer term, photosynthesis-based models may also have the advantage in estimating $g_{\mathrm{s}}$ under future climate change conditions, since the influence of elevated $\mathrm{CO}_{2}$ is directly incorporated in the $g_{\mathrm{s}}$ algorithm.

\section{Conclusions}

In summary, the comparison of observed and modelled $g_{\mathrm{s}}$ for durum wheat, grapevine and birch showed a similar performance for both the multiplicative algorithm and the BWBalgorithm, with the former slightly outperforming the latter in calculating seasonal courses of $g_{s}$. The beech data set proved to be unsuitable for the BWB-algorithm due to its constant irradiance values. In general, both algorithms were able to predict the observed trends over the course of the day and the season, i.e. a steady increase in $g_{\mathrm{s}}$ in the morning, followed by a midday depression, a subsequent recovery and a steady decline from mid-afternoon on, as well as a steady increase in $g_{\mathrm{s}}$ at the beginning of the growing season as shown for 
beech. The main drivers for these trends are thought to be the temperature and VPD. Furthermore, SMD, which couldn't be taken into account in this study, is expected to have a strong effect on the seasonal time course of $g_{\mathrm{s}}$.

However, the performance of the algorithms was not as good as reported in previous studies. This result might be attributed to site-specific model alterations (i.e. not only parameterisation) in previous studies and to the nature of the data used in this study.

A site-specific parameterisation of the algorithms accounting for local growing conditions, which is desirable to validate ozone deposition modelling on a regional scale, reveals the higher input requirements of the BWB-algorithm as compared to the multiplicative algorithm because of the need of the former to first model net photosynthesis $\left(A_{\mathrm{n}}\right)$. The most important input parameters that require precise parameterisation are $g_{\max }$ for the multiplicative and $V_{\mathrm{cmax}}, J_{\max }$ and $m$ for the BWBalgorithm.

In conclusion, this study shows that for present-day applications there is no obvious advantage in replacing the multiplicative with a BWB-algorithm for regional scale ozone deposition modelling schemes. However, advances in data acquisition techniques (e.g. remote sensing and global carbon modelling systems) combined with a more urgent need to include the influence of $\mathrm{CO}_{2}$ under climate change conditions might favour the photosynthesis-based algorithm in the future.

\section{Acknowledgements}

This work was supported by contract SPU24 from the UK Department of the Environment, Food and Rural Affairs. The birch measuring campaign was funded by the Academy of Finland (project 51758)

\section{References}

Arora, V.A., 2003. Simulating energy and carbon fluxes over winter wheat using coupled land surface and terrestrial ecosystem models. Agricultural and Forest Meteorology 118, 21-47.

Ashmore, M.R., 2005. Assessing the future global impacts of ozone on vegetation. Plant, Cell and Environment 28, 949-964.

Baldocchi, D., 1997. Measuring and modelling carbon dioxide and water vapour exchange over a temperate broad-leaved forest during the 1995 summer drought. Plant, Cell and Environment 20, 1108-1122.

Bernacchi, C.J., Singsaas, E.L., Pimentel, C., Portis Jr., A.R., Long, S.P., 2001. Improved temperature response functions for models of Rubisco-limited photosynthesis. Plant, Cell and Environment 24, 253-259.

Ball, J.T., Woodrow, I.E., Berry, J.A., 1987. A model predicting stomatal conductance and its contribution to the control of photosynthesis under different environmental conditions. In: Biggens, J. (Ed.), Progress in Photosynthesis Research, vol. IV. Martinus Nijhoff, Dordrecht, pp. 221-224.

Emberson, L.D., Simpson, D., Tuovinen, J.-P., Ashmore, M.R., Cambridge, H.M., 2000. Towards a Model of Ozone Deposition and Stomatal Uptake over Europe. Norwegian Meteorological Institute, Oslo, EMEP MSC-W Note X/00, pp. 57.

Emberson, L.D., Ashmore, M.R., Simpson, D., Tuovinen, J.-P., Cambridge, H., 2001. Modelling and mapping ozone deposition in Europe. Water, Air, and Soil Pollution 130, 577-582.
Emberson, L.D., Büker, P., Ashmore, M.R., Tuovinen, J.-P., Simpson, D., 2005a. Parameterisation of the $\mathrm{DO}_{3} \mathrm{SE}$ model for forest trees. In: Wieser G., et al. (Eds.), Critical Levels for Ozone: Further Applying and Developing the Flux-based Concept, Innsbruck, Austria.

Emberson, L.D., Massman, W.J., Büker, P., Soja, G., van de Sand, I., Mills, G., Jacobs, C., 2005b. The development, evaluation and application of $\mathrm{O}_{3}$ flux and flux-response models for additional agricultural crops. In: Wieser, G., et al. (Eds.), Critical Levels for Ozone: Further Applying and Developing the Flux-based Concept, Innsbruck, Austria.

Farquhar, G.D., von Caemmerer, S., Berry, J.A., 1980. A biochemical model of photosynthetic $\mathrm{CO}_{2}$ assimilation in leaves of $\mathrm{C}_{3}$ species. Planta 149 $78-90$.

Fuhrer, J., Achermann, B. (Eds.), 1999, Critical Levels for Ozone - Level II. Environmental Documentation, 115. Swiss Agency for Environment, Forest and Landscape, Bern, Switzerland, pp. 215-218.

Grünhage, L., Haenel, H.D., Jäger, H.-J., 2000. The exchange of ozone between vegetation and atmosphere: micrometeorological measurement techniques and models. Environmental Pollution 109, 373-392.

Jacobs, C.M.J., van den Hurk, B.I.J.M., de Bruin, H.A.R., 1996. Stomatal behaviour and photosynthetic rate of unstressed grapevines in semi-arid conditions. Agricultural and Forest Meteorology 80, 111-134.

Jarvis, P.G., 1976. The interpretation of the variations in leaf water potential and stomatal conductance found in canopies in the field. Philosophical Transactions of the Royal Society of London B 273, 593-610.

Jones, H.G., 1992. Plants and Microclimate: A Quantitative Approach to Environmental Plant Physiology, second ed. Cambridge University Press, Cambridge.

Kosugi, Y., Shibata, S., Kobashi, S., 2003. Parameterization of the $\mathrm{CO}_{2}$ and $\mathrm{H}_{2} \mathrm{O}$ gas exchange of several temperate deciduous broad-leaved trees at the leaf scale considering seasonal changes. Plant, Cell and Environment 26, 285-301.

Leuning, R., 1995. A critical appraisal of a combined stomatal-photosynthesis model for $\mathrm{C}_{3}$ plants. Plant, Cell and Environment 18, 339-355.

Leuning, R., 2002. Temperature dependence of two parameters in a photosynthesis model. Plant, Cell and Environment 25, 1205-1210.

Massman, W.J., Musselman, R.C., Lefohn, A.S., 2000. A conceptual ozone dose-response model to develop a standard to protect vegetation. Atmospheric Environment 34, 745-759.

Mauzerall, D.L., Wang, X., 2001. Protecting agricultural crops from the effects of tropospheric ozone exposure: reconciling science and standard setting in the United States, Europe and Asia. Annual Review of Energy and the Environment 26, 237-268.

Misson, L., Panek, J.A., Goldstein, A.H., 2004. A comparison of three approaches to modeling leaf gas exchange in annually drought-stressed ponderosa pine forests. Tree Physiology 24, 529-541.

Müller, J., Wernecke, P., Diepenbrock, W., 2005. LEAFC3-N: a nitrogensensitive extension of the $\mathrm{CO}_{2}$ and $\mathrm{H}_{2} \mathrm{O}$ gas exchange model LEAFC3 parameterised and tested for winter wheat (Triticum aestivum $\mathrm{L}$.) Ecological Modelling 183, 183-210.

Nikolov, N.T., 1997. Mathematical Modelling of seasonal Biogeophysical Interactions in Forest Ecosystems. PhD thesis, Colorado State University, pp. 149.

Nikolov, N.T., Zeller, K.F., 2003. Modeling coupled interactions of carbon, water, and ozone exchange between terrestrial ecosystems and the atmosphere. I: model description. Environmental Pollution 124, 231-246.

Nikolov, N.T., Massman, W.J., Schoettle, A.W., 1995. Coupling biochemical and biophysical processes at the leaf level: an equilibrium photosynthesis model for leaves of C3-plants. Ecological Modelling 80, 205-235.

Oksanen, E., 2003. Responses of selected birch (Betula pendula Roth) clones to ozone change over time. Plant, Cell and Environment 26, 875-886.

Simpson, D., Fagerli, H., Jonson, J.E., Tsyro, S., Wind, P., 2003. Transboundary Acidification, Eutrophication and Ground Level Ozone in Europe. Part I: Unified EMEP Model Description. Norwegian Meteorological Institute, Oslo. <http://www.emep.int/publ/common_publications.html > EMEP MSC-W Note 1/2003104p.

de la Torre, D., 2004. Efectos del ozono troposférico sobre la producción relativa de trigo y cebada mediterráneos. Modulación por factores ambientales. PhD thesis, Universidad Autónoma de Madrid, pp. 280. 
Tuovinen, J.-P., Simpson, D., Mikkelsen, T.N., Emberson, L.D., Ashmore, M.R., Aurela, M., Cambridge, H.M., Hovmand, M.F., Jensen, N.O., Pilegaard, K., Ro-Poulsen, H., 2001. Comparisons of measured and modelled ozone deposition to forests. Water, Air and Soil Pollution: Focus 1, 263-274.

Uddling, J., Hall, M., Wallin, G., Karlsson, P.E., 2005. Measuring and modelling stomatal conductance and photosynthesis in mature birch in Sweden. Agricultural and Forest Meteorology 132, 115-131.

Van Wijk, M.T., Dekker, S.C., Bouten, W., Bosveld, F.C., Kohsiek, W. Kramer, K., Mohren, G.M.J., 2000. Modeling daily gas exchange of a Douglas-fir forest: comparison of three stomatal conductance models with and without a soil water stress function. Tree Physiology 20, 115-122.

Weinstein, D.A., Beloin, R.M., Yanai, R.D., 1991. Modeling changes in red spruce carbon balance and allocation in response to interacting ozone and nutrient stress. Tree Physiology 9, 127-146.

Weinstein, D.A., Samuelson, L.J., Arthur, M.A., 1998. Comparison of the response of red oak (Quercus rubra) seedlings and mature trees to ozone exposure using simulation modelling. Environmental Pollution 102, $307-320$.

Wieser, G., Häsler, R., Götz, B., Koch, W., Havranek, W.M., 2000. Role of climate, crown position, tree age and altitude in calculated ozone flux into needles of Picea abies and Pinus cembra: a synthesis. Environmental Pollution $109,415-422$.

Wohlfahrt, G., Bahn, M., Horak, I., Tappeiner, U., Cernusca, A., 1998. A nitrogen sensitive model of leaf carbon dioxide and water vapour gas exchange: application to 13 key species from differently managed mountain grassland ecosystems. Ecological Modelling 113, 179-199.

Working Group on Effects, 2004. Review and Assessment of air pollution effects and their recorded trends. Working Group on Effects, Convention on Long-range Transboundary Air Pollution. National Environment Research Council, UK.

Wullschleger, S.D., 1993. Biochemical limitations to carbon assimilation in C3 plants - a retrospective analysis of the $A / C$ i curves from 109 species. Journal of Experimental Botany 44, 907-922. 